\title{
Synthesis, Spectral Characterization and Antibacterial activity of Functionalized Hydrazones
}

\author{
D. KASIMBI ${ }^{1}$, K. HUSSAIN REDDY ${ }^{1 *}$ and N. DEVANNA ${ }^{2}$ \\ ${ }^{1}$ Department of Chemistry, Sri Krishnadevaraya University, Ananthapuramu-515 003, India. \\ ${ }^{2}$ Department of Chemistry, Jawaharlal Nehru Technological University, Ananthapur-515 002. India \\ ${ }^{*}$ Corresponding author E-mail: khussainreddy @ yahoo.co.in \\ http://dx.doi.org/10.13005/ojc/350208
}

(Received: January 04, 2019; Accepted: March 31, 2019)

\begin{abstract}
New hydrazones have been synthesized by condensing 2-acetylthiophene with acetic hydrazide and benzhydrazide. The synthesized hydrazones viz. 2-acetylthiophene acetoylhydrazone (ATAH), 2-acetylthiophene benzoylhydrazone (ATBH) are characterized in the light of physicochemical and analytical data. Structures of ATAH and ATBH are confirmed by FT-IR, ${ }^{1} \mathrm{H}-\mathrm{NMR}$ and Mass spectral data. The hydrazones are screened for their anti-bacterial activities against $E$ coli, Bacillus cereus, Staphylococcus aureus and Pseudomonas aureoginos. Acetoyl hydrazones are found to show more antibacterial activity than the corresponding benzoyl hydrazones.
\end{abstract}

Keywords: Synthesis, Characterization, Functionlized Hydrazones, Antibacterial action.

INTRODUCTION

Hydrazones having an azomethine ( $>\mathrm{C}=\mathrm{N}-\mathrm{NH}-)$ aggregate establish an imperative class of ligands for new advancements in medication ${ }^{1}$. In this way, it is of interest to prepare new hydrazones and to evaluate their biological activities. Hydrazones possess diverse biological and pharmacological properties ${ }^{2,3}$ such as antimicrobial ${ }^{4}$, anti-tubercular ${ }^{5}$ anticonvulsant ${ }^{6}$, anti-inflammatory ${ }^{7}$, analgesic, antifungal, vasodilator ${ }^{8}$, antiviral, anticancer ${ }^{9.10}$, antiplatelet, antimalarial, cardio protective, antihelmintic, antiprotozoal, antitrypanosomal, cytotoxic ${ }^{11}$ and antischistosomiasis activities. The chemical properties of hydrazones have been widely investigated due to their chelating capability ${ }^{12}$, pharmacological activity ${ }^{13,14}$ and analytical applications ${ }^{15,16}$. Survey of literature ${ }^{1,17,18}$ revealed that hydrazones possessing heterocyclic group show interesting biological and pharmacological properties.

Thiophenes are important class of heterocyclic compounds. Thiophene derivatives are widely used as building blocks in many pharmaceuticals ${ }^{19}$. Thiophene derivatives are well known for their therapeutic applications. Thiophene nucleus is one of the most important heterocycles exhibiting remarkable pharmacological activities ${ }^{20}$. For example, 2-butylthiophene has been used as a raw material in the synthesis of anticancer agents.

In the light of the above literature and in

This is an Open Access article licensed under a Creative Commons license: Attribution 4.0 International (CC- BY). Published by Oriental Scientific Publishing Company @ 2018

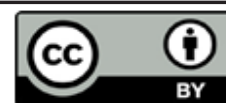


continuation of our progressing research work, here in we report synthesis, spectral characterization and antibacterial activity of 2-acetylthiophene acetoylhydrazone(ATAH), 2-acetylthiophene benzoylhydrazone (ATBH).

\section{EXPERIMENTAL}

2-acetylthiophene (AR grade) was procured from Sigma-Aldrich Chemicals Pvt. Ltd. India. Acetic hydrazide and benzhydrazide were purchased from Merck chemicals. N,N- dimethyl formamide(DMF), ethanol were of AR quality and utilized as provided. Elemental data were obtained using a PerkinElmer $2400 \mathrm{CHNS/O}$ analyzer. Mass spectra (in El+ ionization mode) of compounds were recorded using JEOLGCMATEIIGC-Mass spectrometer. IR spectra of hydazones in solid state were recorded in $4000-400 \mathrm{~cm}^{-1}$ range on a Perkin-Elmer $100 \mathrm{FT}$-IR spectrophotometer. ${ }^{1} \mathrm{H}-\mathrm{NMR}$ spectra were recorded using Avanc-400 Brucker, NMR spectrometer.

\section{Preparation of 2-acetylthiophene acetoylhydrozone} (ATAH)

A $3.0 \mathrm{~g}$ (0.03) of acetic hydrazide dissolved in $20 \mathrm{ml}$ methanol was added to a hot methanolic solution $(20 \mathrm{ml})$ of 2-acetylthiophene $(0.03 \mathrm{~mol}, 5.03$ $\mathrm{ml}$ )in a $100 \mathrm{ml}$ round bottom flask. Glacial acetic acid (3-4drops) was added to the reaction mixture. The contents were refluxed over water bath for $2 \mathrm{~h}$ and cooled to room temperature. The crystalline compound formed was obtained by filtration. It was washed a few times with hot water, recrystallized from methanol and dried in vacuo. Yield: $85 \%$ M.P: $176-178^{\circ} \mathrm{C}$. Preparation of 2-acetylthiophene acetoylhydrozone (ATAH) is shown in Scheme 1.

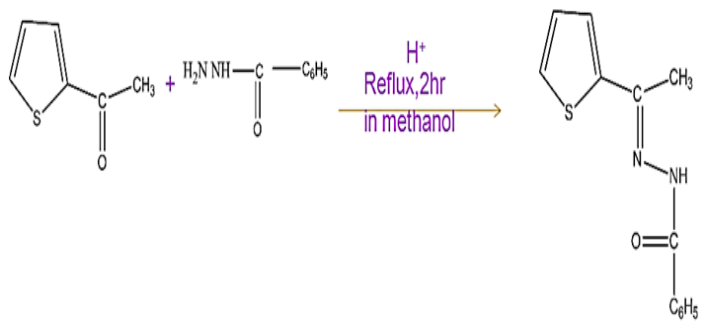

Scheme 1. Synthesis of 2-acetylthiophene acetoylhydrozone (ATAH)

Preparation of 2-acetylthiophene Benzoyl hydrozone (ATBH)

A $3 \mathrm{~g}(0.02 \mathrm{~mol})$ of benzhydrazide dissolved in $20 \mathrm{ml}$ methanol was added to a hot methanolic solution $(20 \mathrm{ml})$ of 2 -Acetylthiophene $(0.03 \mathrm{~mol}$, $2.7 \mathrm{ml}$ ) in a $100 \mathrm{ml}$ round bottom flask. Glacial acetic acid (3-4 drops) was added to the reaction mixture. The contents were refluxed over water bath for 2 $\mathrm{h}$ and cooled to room temperature. The crystalline compound formed was collected by filtration, washed several times with hot water, recrystallized from methanol and dried in vacuo. Yield, 85\%; M.P., $198-200^{\circ} \mathrm{C}$. Preparation of 2-acetylthiophene benzoylhydrozone (ATBH) is shown in Scheme 2.

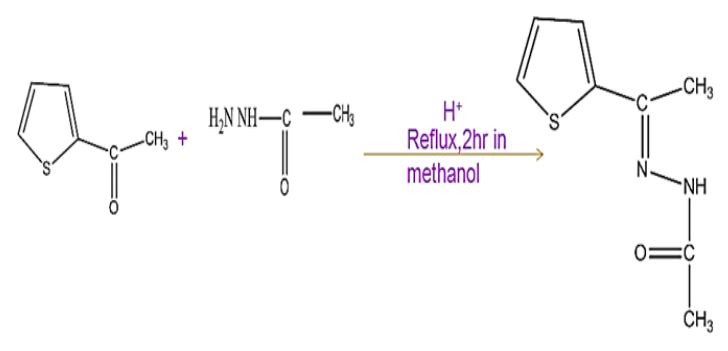

Scheme 2. Synthesis of 2-acetylthiophene benzoylhydrozone (ATBH)

The antibacterial activity of hydrazones were screened against the Bacillus subtilis and Staphylococcus aureus which are gram positive and Pseudomonas aureoginosa and Escherichia coli which are gram negative organisms

\section{Antibacterial Activity}

Procedure for the Development Media: Bacillus subtilis and Staphylococcus aureus which are gram positive and Pseudomonas aureoginosa and Escherichia coli which are gram negative organisms were chosen in light of their clinical and pharmacological significance. The bacterial strains were got from Division of Microbiology, Osmania College, Hyderabad. Activities of present hydrazones are investigated on these microorganisms. The bacterial stock societies were hatched for one day at $37^{\circ} \mathrm{C}$ on supplement agar. The microscopic organisms were developed on Mueller-Hinton agar plates at $37^{\circ} \mathrm{C}$. The stock cultures were kept up at $4^{\circ} \mathrm{C}$ for the development of organisms potato dextrose agar was utilized. Antibacterial activity of hydrazones was determined by using zone of hindrance technique

\section{Preparation of Discs}

Whatman No.1 channel paper plates of $5 \mathrm{~mm}$ width were autoclaved by keeping in a spotless 
and dry Petri plate. The plates were absorbed compound answers for $5 \mathrm{~h}$ were taken as test material. Following $5 \mathrm{~h}$ the circles were dried in shade. The groupings of compound arrangements per plate are represented $0.1 \mathrm{~g} / 1 \mathrm{ml}$. In this manner they were cautiously exchanged to spread on refined Petri plates. Channel paper plates inundated in ethanol are arranged and utilized as positive control and streptomycin as negative control.

\section{Testing of antibacterial activity}

LB agar medium was prepared and it was sanitized at $121^{\circ} \mathrm{C}$ for 30 minutes. The agar plates were prepared ${ }^{21}$ by pouring about $10 \mathrm{ml}$ of the medium into $10 \mathrm{~cm}$ Petri dishes under aseptic condition and left undisturbed for $2 \mathrm{~h}$ to harden the medium. $1 \mathrm{ml}$ of inoculum (containing suspension) of microorganisms culture (Bacillus subtilis, Staphylococcus aureus, Pseudomonas aureoginosa and Escherichia coli) was poured on to the plates independently containing set agar media. The prepared sterile channel paper circles were impregnated with the sample solution and shaken completely and these test plates hatched for 2 days at $37^{\circ} \mathrm{C}$ for the improvement of inhibitory zones and the average of two readings were recorded.

\section{Measuring the diameter of inhibition zone}

The inhibition zones were measured after 1 day at $37^{\circ} \mathrm{C}$. The diameter of the inhibition zone was measured and recorded with the aid of plastic ruler. Five paper discs placed in one Petri plate.

\section{RESULTS AND DISCUSSION}

The hydrazones are partially soluble in water, less soluble methanol more soluble in ethanol and readily soluble in acetonitrile $\left(\mathrm{CH}_{3} \mathrm{CN}\right)$, DMF and DMSO. The colours, formula weight, yields and elemental analysis of hydrazones are summarized in Table 1

Table 1: Physicochemical and analytical data of hydrazones

\begin{tabular}{cccccccc}
\hline S.No & Hydrazone & Mol.Wt. & Colour & Yield\% & \%C Found (Calc.) & \%H Found (Calc.) & \%N Found (Calc.) \\
\hline 01 & ATAH & 182 & Colourless & 85 & $53.25(52.74)$ & 5.525 .49 & $15.30(15.38)$ \\
02 & ATBH & 244 & Pale White & 83 & $64.50(63.93)$ & $4.85(4.91)$ & $11.60(11.47)$ \\
\hline
\end{tabular}

The hydrazones are further characterized using (i) Fourier-Transform Infrared spectroscopy, (ii) NMR spectroscopy and (iii) Mass spectrometry (i)

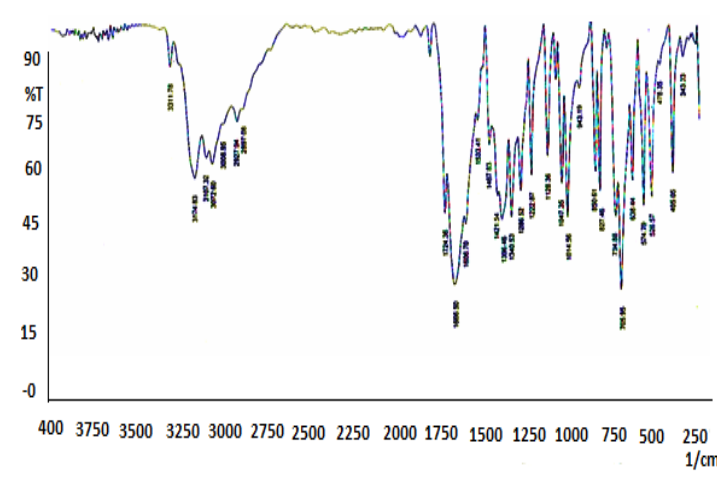

Fig. 1. IR spectrum of ATAH in $\mathrm{KBr}$ medium

Fig. 2. IR spectrum of ATBH in $\mathrm{KBr}$ medium

\begin{tabular}{ccc}
\hline ATAH & ATBH & Assignment \\
\hline 3312 & 3327 & vNH (stretching) \\
3072 & 3073 & $v C H$ (Aromatic stretching) \\
2928 & - & $v C H$ (Aliphatic stretching) \\
1666 & 1651 & vC=O (stretching) \\
1606 & 1576 & vC=N (stretching) \\
1017 & 1020 & vN-N (stretching) \\
\hline
\end{tabular}

FT-IR spectroscopy: IR spectra of ATAH and ATBH are shown in Fig. 1 and 2 respectively. IR spectral data values and assignment of peaks are given in Table 2 .

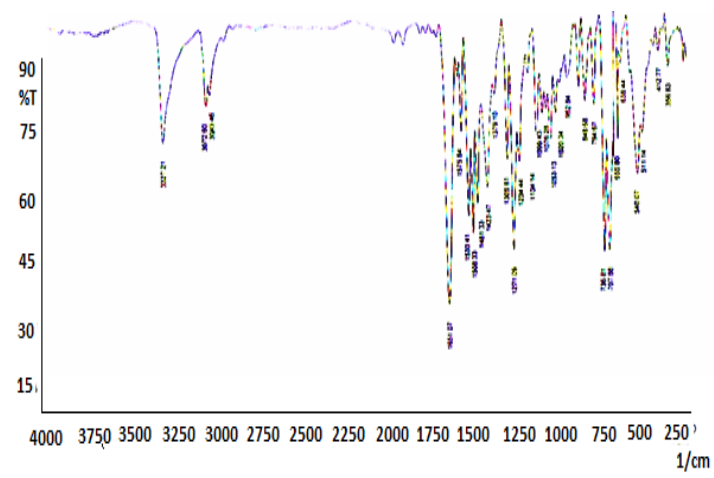

Fig. 2. IR spectrum of ATBH in $\mathrm{KBr}$ medium

\section{(ii) ${ }^{1} \mathrm{H}-\mathrm{NMR}$ spectroscopy}

${ }^{1} \mathrm{H}-\mathrm{NMR}$ spectra of ATAH and ATBH are shown in Fig. 3 and 4 respectively. Peak assignments are given in Table 3 .

(iii) Mass spectra Mass spectra of ATAH and ATBH are shown 
in Fig. 5 and 6 respectively. Fragmentation Schemes are given in Figs. 7 and 8.

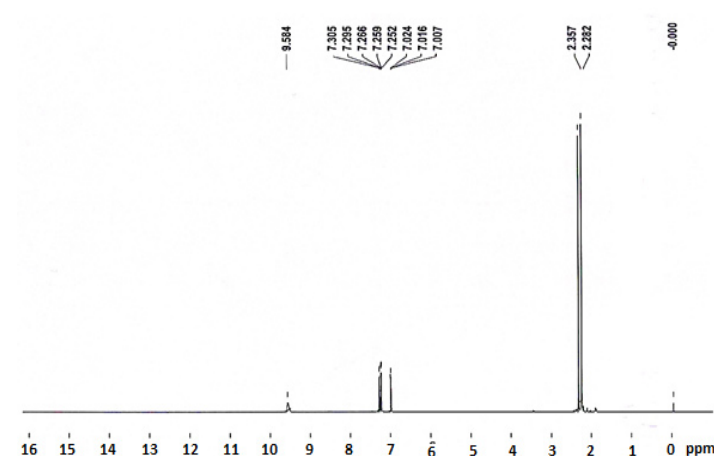

Fig. 3. ${ }^{1} \mathrm{H}-\mathrm{NMR}$ spectrum of ATAH in $\mathrm{CDCl}_{3}$

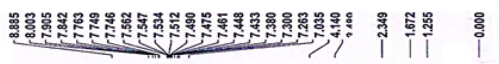

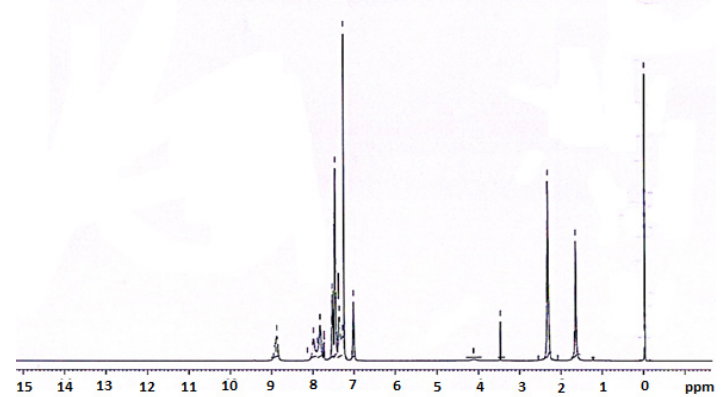

Fig. 4. ${ }^{1} \mathrm{H}-\mathrm{NMR}$ spectrum of ATBH in $\mathrm{CDCl}_{3}$

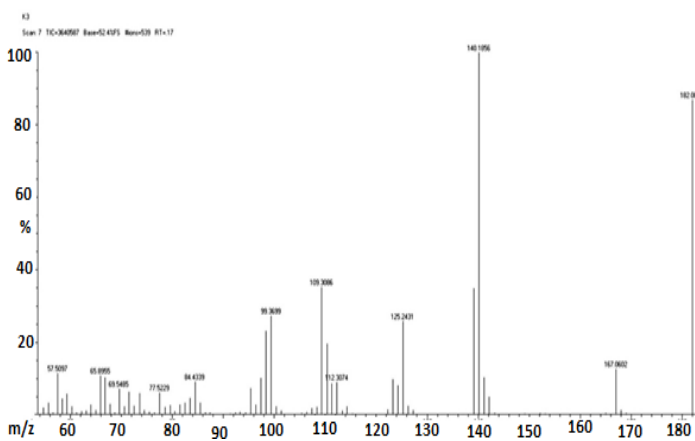

Fig. 5. Mass spectrum of ATAH

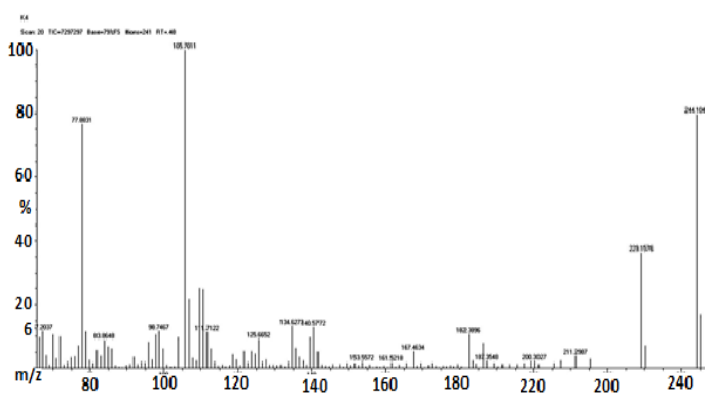

Fig. 6. Mass spectrum of ATBH
Table 3: Assignment of peaks observed in NMR spectra of ATAH and ATBH

\begin{tabular}{|c|c|c|c|c|}
\hline Hydazone & $\begin{array}{l}\text { Chemical } \\
\text { Shift(ppm) }\end{array}$ & Multiplicity & $\begin{array}{l}\text { No. of } \\
\text { protons }\end{array}$ & Assignment \\
\hline \multirow{4}{*}{ ATAH } & 2.28 & Singlet & 3 & Acetoyl $\mathrm{CH}_{3}$ \\
\hline & 2.35 & Singlet & 3 & Acetoyl $\mathrm{CH}_{3}^{3}$ \\
\hline & $7.00-7.30$ & Multiplet & 3 & Thiophene $\mathrm{H}$ \\
\hline & 9.5 & Singlet & 1 & Imine $\mathrm{H}$ i.e., $>\mathrm{NH}$ \\
\hline \multirow[t]{3}{*}{ ATBH } & 2.34 & Singlet & 3 & Acetyl $\mathrm{CH}_{3}$ \\
\hline & $7.03-8.00$ & Multiplet & 8 & $\begin{array}{c}\text { Thiphene } \mathrm{H}^{3}+ \\
\text { Benzoyl H}\end{array}$ \\
\hline & 8.885 & Singlet & 1 & Imine $\mathrm{H}$ i.e., $>\mathrm{Nh}$ \\
\hline
\end{tabular}

Mass spectra of ATAH and ATBH show molecular ion peak at $\mathrm{m} / \mathrm{z}$ values 182 and 244 respectively corresponding to their molecular weights. According to nitrogen rule even mass numbers of ATAH and ATBH indicate even number of nitrogen atoms. Fragmentation Scheme of ATAH is shown in Figure 7.

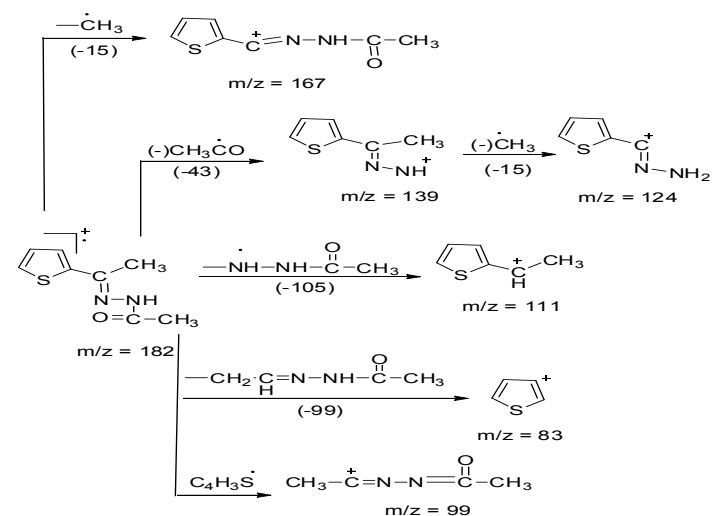

Fig. 7. Mass fragmentation Scheme of ATAH

Mass fragmentation pattern scheme of ATBH is given in Figure 8

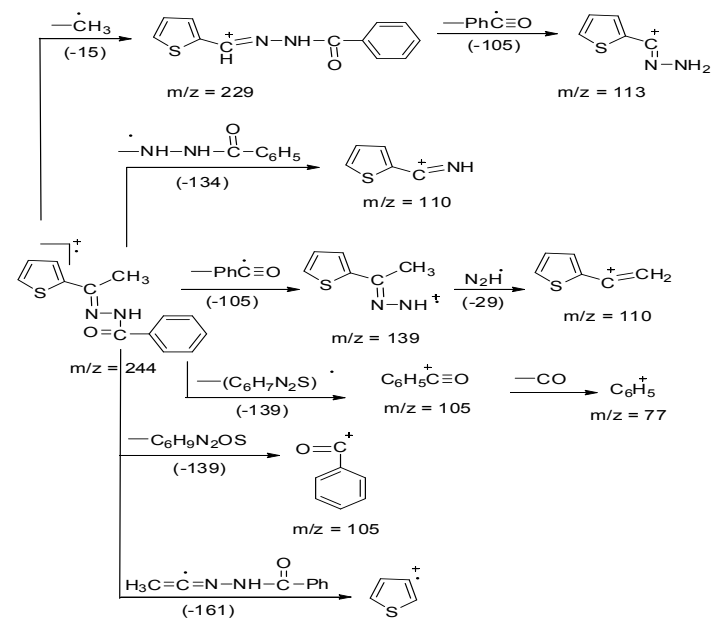

Fig. 8. Mass fragmentation Scheme of ATBH 
The diameters of the zones of complete inhibition were measured in millimeters $(\mathrm{mm})$ and data are given in the Table 4.

\section{Antibacterial assay}

The antibacterial activity of hydrazones were screened against the Bacillus subtilis and Staphylococcus aureus which are Gram positive and Pseudomonas aureoginosa and Escherichia coli which are Gram negative organisms. Typical photographs are shown Figure 9.

The antibacterial activities of our hydrazone compounds are comparable to with standard drug Streptomycin. Acetoyl hydrazones (APAH and ATAH) compounds show more activity when compared with benzoyl hydrazone(APBH and ATBH) compounds, All the compounds show gradually increasing activity with concentrations towards both gram positive and gram negative bacterial species but at maximum concentrations the activity is not as expected due to less diffusion rate in agar medium.

In our present study we are investigating our compounds which are more antibacterial in nature and it makes platform for preparation of effective chemotherapeutics agents for therapy of human pathogenic diseases.

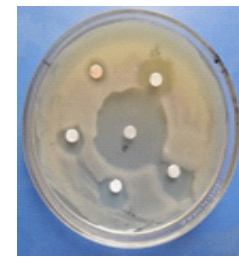

Bacillus

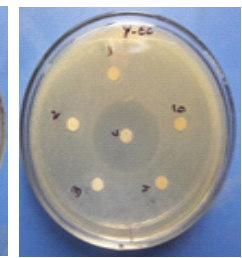

E.Coli

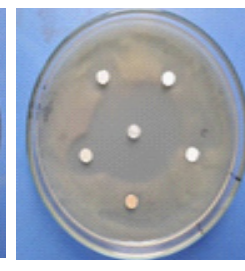

Staphylococcus
Fig. 9. Typical photographs of agar plates showing antibacterial activity of 1)APAH, 2) APBH, 3)ATAH, 4) ATBH, 5) Etanol blank(Control) and 6) Streptomycin(Reference)

Table 4: Antibacterial activity of a group of closely ATAH and ATBH and closely related Hydrazones (Zone of inhibition is given in $\mathrm{mm}$ )

\begin{tabular}{lccccccccccccc}
\hline Compound & E Coli & \multicolumn{1}{c}{} & \multicolumn{3}{c}{ Bacillus } & & \multicolumn{3}{c}{ Staphylococcus aureus } & P.aureoginosa \\
& A & B & C & A & B & C & A & B & C & A & B & C \\
\hline APAH1 & 4.2 & 5.6 & 6.6 & 5.0 & 6.0 & 6.5 & 7.0 & 8.0 & 9.0 & 7.0 & 8.0 & 8.5 \\
APBH2 & 2.0 & 4.0 & 6.0 & 5.0 & 5.5 & 6.0 & 4.0 & 6.0 & 8.0 & 6.0 & 7.0 & 7.5 \\
ATAH3 & 4.0 & 6.0 & 6.5 & 5.0 & 6.0 & 7.0 & 6.0 & 8.0 & 9.0 & 5.0 & 5.0 & 6.0 \\
ATBH4 & 5.5 & 4.5 & 5.5 & 4.0 & 5.0 & 6.0 & 4.0 & 6.0 & 7.0 & 5.0 & 5.0 & 6.0 \\
Streptomycin & 5.5 & 6.6 & 7.5 & 6.6 & 7.5 & 9.5 & 10.0 & 12.0 & 13.0 & 6.0 & 8.0 & 10.0 \\
\hline
\end{tabular}

$1 \mathrm{APAH}=2$-Acetylpyridine acetoylhydrazone $: 2 \mathrm{APBH}=2$-Acetylpyridine benzoylhydrazone

$3 A T A H=2$-Acetylthiophene acetoylhydrazone: 4 ATBH = 2-Acetyl thiophene benzoylhydrazone

Compound Taken: $\mathrm{A}=200 \mu \mathrm{g} ; \quad \mathrm{B}=300 \mu \mathrm{g} ; \quad \mathrm{C}=500 \mu \mathrm{g}$

\section{CONCLUSION}

We have synthesized and characterized two closely related functionalized hydrazones bearing thiophenemoiety and evaluated their anti-bacterial activity. Acetoyl hydrazones are found to show more antibacterial activity than the corresponding benzoyl hydrazones.

\section{ACKNOWLEDGEMENT}

KHR gratefully acknowledges the financial assistance provided by UGC, New Delhi in the form of One-time Grant Scheme [ Lr. No. F. 19-106/2013 (BSR)]. The authors also thank UGC and DST, New Delhi for giving equipment facility under SAP and FIST programs respectively. Further, the authors thank SAIF, IIT-M for providing ${ }^{1} \mathrm{H}-\mathrm{NMR}$ and Mass spectral data.

\section{CONFLICT OF INTEREST}

The authors declare that there is no conflict of interests regarding the publication of this article.

\section{REFERENCES}

1. Moksharagni, B.; Hussain Reddy, K. European Journal of Biomedical Pharmaceutical Sciences., 2018, 5, 810-817.
2. Verma, G.; Akranth M.; Mohammad S.; Akhtar, M.; Rahmat Ali, M.; Mohammad Mumtaz Alam, M. J Pharm Bioallied Sci., 2014, 6, 69-80. 
3. Uppal, G.; Bala, S.; Kamboj, S.; Saini, M. Der Pharma Chem., 2011, 3, 250-68.

4. Zani, V.P.; Cozzini, F.; Doytchninova, P.I. Eur J. Med. Chem., 2002, 37, 553.

5. Sah, P.P.T.; Peoples, S. A. Journal of American Pharmacists Association, 1954, 43, 513-524; Rollas, S. Farmaco., 2002, 57, 595.

6. Ragavendran, J.V.; Sriram, D.; Patel, S.K.; Reddy, I.V.; Bharatwajan, N.; Stables, J.Yogeswari, P. Eur. J. Med. Chem., 2007, 42, 145.

7. Bezerra-Netto, H.J.C.; Lacerda, D.I.; Miranda, A.I. P.; Alves, H.M.; Barreiro, E.J.; Fraga, C.A.M. Bio-org. Med. Chem., 2006, 4, 7924.

8. Kummerle, A.E.; Raimundo, J.M.; Leal, C.M.; De Silva G.S.; Balliano, T.L.; Pereira,M.A.; Simone, C.A. ; Sudo, T.T.; Zapata-Sudo, G.; Fraga C.A.M.; Barreiro E.J. Eur. J. Med. Chem., 2009, 44, 4004.

9. Easmon, J.; Purstinger, G.; Roth, T.; Fiebig, H.; Jenny, M.; Jaeger, W.; Heinisch, G.; Hof mann, J. Int. J. Cancer., 2001, 94, 89.

10. Richardson, D.R.; Kalinowski, D.S.; Richardson, V.; Sharpe, P.C.; Lovejoy, D.B.; Islam M.; Bernhardt, J. Med. Chem., 2009, 52, 1459.
11. Avaji, P.G.; Kumar C.H.V.; Patil, S.A.; Shivananda, K.N.; Nagaraju C.; Eur J. Med. Chem., 2009, 44, 3552.

12. Raman, N.; Ravichandran, S.; Thangaraja, C.; J. Chem. Sci., 2004, 116, 215-219.

13. Sunita Devi, O.; Singh, A.K.; J. Chem. Pharm. Res., 2011, 3, 1055-1060.

14. Ramesh, C. Synthesis and Reactivity in Inorganic and Metal-Organic Chemistry, 1993, 23, 257-267.

15. Syed Tajudeen, S.; Radha, E. Asian J. Chem., 2009, 29, 313-316.

16. Garg B.S.; Singh, P.K.; Garg, S.K. Indian J. Chem., 1991, 30A, 979-981.

17. Xin, S.; Ivan, A.; Chem. Soc. Reviews., 2014, 43, 1963.

18. Rollas, S.; Küçükgüze, S.G. Molecules., 2007, 12, 1910- 1939.

19. Jha, K.K.; Kumar, S.; Tomer, I.; Mishra, R.; J. Pharm. Res., 2012, 5, 560-566.

20. Mishra, R.; Tomar, L.; Singhal, S.; Jha, K.K.; Der Pharma Chemica., 2011, 3, 38-54.

21. Perez, C.; Paul, M.; Bazerque, P. Actabiol. Med. Exp., 1990, 15, 113-115. 